\title{
Highly Functional Group Tolerant, $(E)$-Selective Transfer Semihydrogenation of Alkynes Catalysed by Iridium Complex Bearing Unsymmetrical Ferrocene-Based Phosphine Ligand
}

\author{
Rafał Kusy $^{*}$, Marcin Lindner ${ }^{\dagger}$, Jakub Wagner ${ }^{\dagger}$, Karol Grela* \\ Institute of Organic Chemistry, Polish Academy of Sciences, Kasprzaka 44/52, 01-224 Warsaw, \\ Poland, e-mail: karol.grela@gmail.com,raphal.qs@gmail.com
}

Keywords: semihydrogenation, alkynes, iridium, homogeneous catalysis

\begin{abstract}
Herein, we present $(E)$-selective transfer semihydrogenation of alkynes based on in situ generated iridium complex from $[\mathrm{Ir}(\mathrm{COD}) \mathrm{Cl}]_{2}$ and unsymmetrical ferrocene-based phosphine ligand in the presence of formic acid as a hydrogen donor. The catalytic system is distinguished by unprecedented chemoselectivity and exceptional stereoselectivity substantiated by the broad scope of tested substrates, including natural products derivatives. The uniform reaction conditions may be applied to various alkynes, owing to a lack of over-reduction. The intriguing difference in catalytic activity between unsymmetrical and symmetrical ferrocene-based ligands was attributed to divergent coordination and steric hindrance. The presented methodology constitutes a solution to the common limitations of the published catalytic systems.
\end{abstract}

\section{INTRODUCTION}

The hydrogenation of unsaturated C-C bonds plays a vital role in organic synthesis. ${ }^{1}$ Hitherto, many methods of alkenes reduction were developed. Notwithstanding the above, functional group tolerance of this transformation was a primary concern. ${ }^{2}$, In 2021, Norton et al. provided a solution to this issue by introducing the highly chemoselective rhodium-based catalytic system (Scheme 1a). ${ }^{3}$ Notably, easily reducible groups such as formyl, keto nitro, nitrile, or dithiane are tolerated, and this methodology was proven to be a perfect tool for late-stage hydrogenation of complex pharmaceuticals.

Alkenes are ubiquitous organic compounds of immense importance to the chemical ${ }^{4}$, pharmaceutical $^{5,6}$, and perfume industries ${ }^{7}$. In comparison to olefins reduction, semihydrogenation of triple C-C bonds, which constitutes one of the methods of alkenes production, is undoubtedly more challenging. In addition to chemoselectivity, the efficacy of this process requires stereoselectivity control and eradication of over-reduction. The first $(Z)$-selective system for alkyne semihydrogenation was developed by Lindlar and based on a heterogeneous palladium catalyst. ${ }^{8}$ Complementary Birch reduction, using alkali metals in liquid ammonia, enabled the production of $(E)$ alkenes. ${ }^{9-10}$ Nonetheless, the limitations of these well-known methods encouraged scientists to 
seek better solutions. Hitherto, catalytic systems for direct ${ }^{11}$ or transfer semihydrogenation ${ }^{12}$ of a triple $\mathrm{C}-\mathrm{C}$ bond were invented. The former approach requires an application of gaseous hydrogen, often under high pressure maintained by sophisticated equipment, which might be inconvenient to the experimenter (Scheme 1b). Thus, various hydrogen donors were tested and utilized in alkyne $(Z)$-semireduction, namely: ammonia-borane ${ }^{13}$, silanes ${ }^{14}$, alcohols ${ }^{15}$, water ${ }^{16}$, or formic ac$\mathrm{id}^{17}$. In particular, the last one is a promising hydrogen storage medium of which dehydrogenation leads to the evolution of nontoxic, gaseous carbon dioxide. ${ }^{18}$

Transfer hydrogenation was also employed in the more demanding synthesis of $(E)$-alkenes. Nonetheless, the published methods were not devoid of various limitations (Scheme 1c). One of them is a lack of complete stereoselectivity control leading to a mixture of isomers and thus affecting the yield and purification process of products. ${ }^{19-22}$ An illustration of this may be work by Sun et al. regarding iridium-based catalytic system using ethanol as a hydrogen donor. ${ }^{23}$ Another limitation is the over-reduction of the triple $\mathrm{C}-\mathrm{C}$ bond resulting in the formation of undesired alkane. Huang et al. reported on a unique system based on an iridium pincer catalyst of which a color change may be used to detect an endpoint of the semihydrogenation process. ${ }^{24}$ Nonetheless, each reaction must be controlled to avoid subsequent over-reduction, which may be inconvenient to the experimenter.

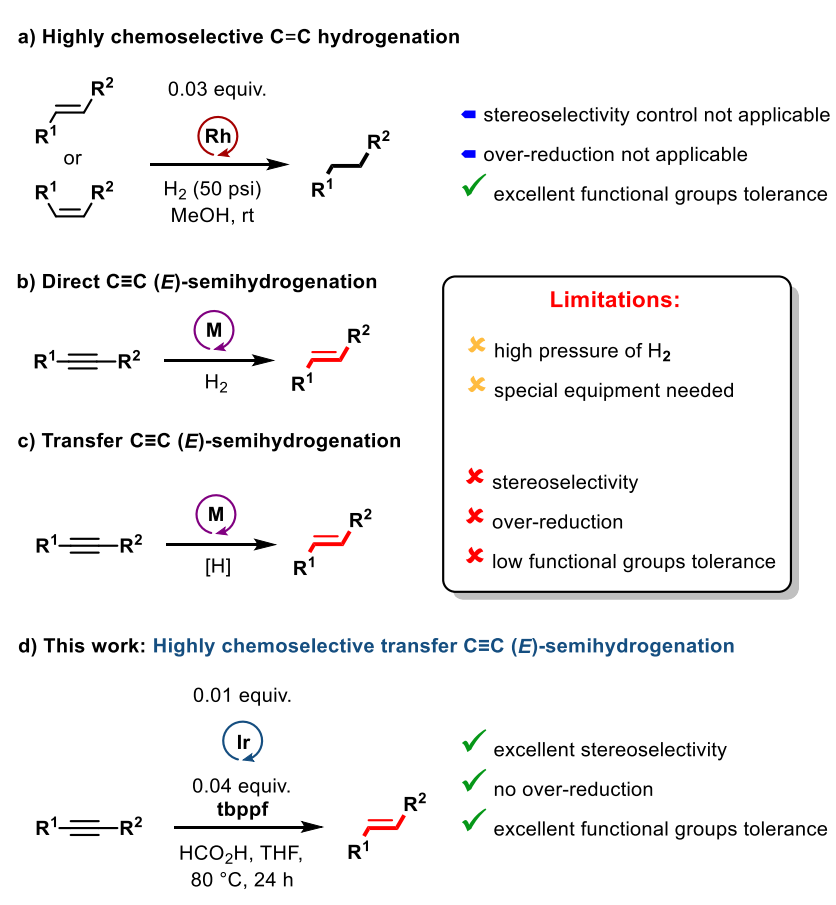

Scheme 1. Methods of unsaturated C-C bonds hydrogenation.

Furthermore, the majority of published semihydrogenation methods suffer from insufficient chemoselectivity. In particular, easily reducible functional groups such as formyl ${ }^{25}$, keto ${ }^{20}$, 26, nitro $^{19-20,22,25,27,28-29}$, cyano $^{30}$, or aryl halides ${ }^{21,} 26$ are not tolerated. In many cases, explicit infor- 
mation concerning the compatibility of the above functional groups was not provided, which may obscure the actual efficiency of a given catalytic system. ${ }^{21,23-24,26,28-29,31-33}$

Herein, we provide a solution to the above limitations introducing a highly chemo- and stereoselective iridium-based protocol for transfer $(E)$-semihydrogenation of a triple C-C bond (Scheme 1d). In addition to a broad scope of alkynes bearing various functional groups, the wide applicability of our methodology was proven by the synthesis of natural products derivatives.

\section{RESULTS}

Optimization of the reaction conditions. During the quest for alternatives to our previously developed catalytic system based on ruthenium complexes ${ }^{34}$, we discovered that $[\operatorname{Ir}(\mathrm{COD}) \mathrm{Cl}]_{2}$ in the presence of formic acid is capable of $(E)$-selective semihydrogenation of diphenylacetylene (Table 1, entry 1). Nonetheless, a significant amount of the over-reduction product formed along with stilbene makes this method inefficient.

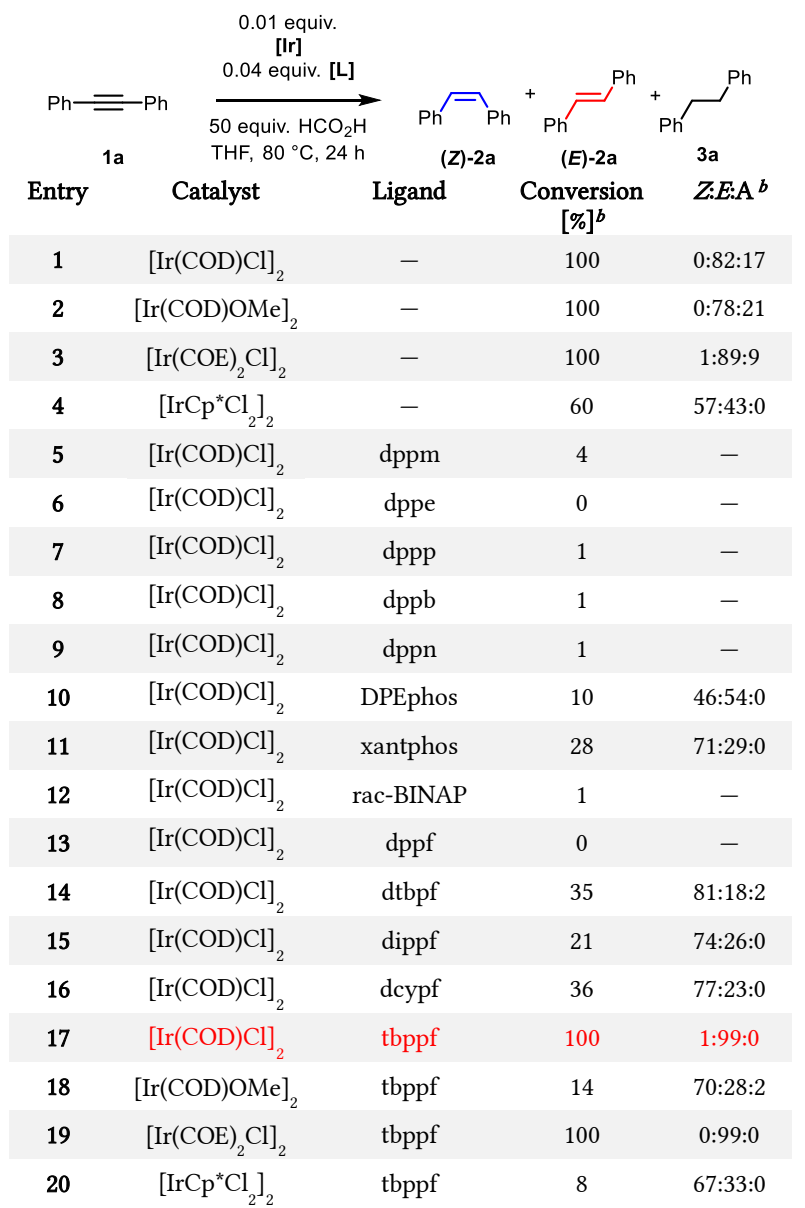

Table 1. Screening of Catalysts and Ligands. ${ }^{a}$ Conditions: 0.01 equiv. [Ir], 0.04 equiv. [L], 50 equiv. $\mathrm{HCO}_{2} \mathrm{H}$, solvent, $80^{\circ} \mathrm{C}$. Isolated yields. ${ }^{b}$ Conversion and products distribution were determined by GC analysis.

Another disadvantage is the production of metallic iridium, which is difficult to remove from the reaction vessel. Thus, other commercially available ruthenium complexes were tested (Figure 1). The use of $[\operatorname{Ir}(\mathrm{COD}) \mathrm{OMe}]_{2}$ gave similar results (Table 1 , entry 2$)$, while $\left[\operatorname{Ir}(\mathrm{COE})_{2} \mathrm{Cl}\right]_{2}$ led to a 
slightly lower over-reduction. In the case of $\left[\mathrm{IrCp}^{*} \mathrm{Cl}_{2}\right]_{2}$, the full conversion was not obtained. Hence, various bidentate phosphine ligands were employed in the model reaction (Figure 1). Application of dppm and its homologs completely obstructed the semihydrogenation process (Table 1, entries 5-8). A similar result was observed when dppn was used (Table 1, entry 9). Employment of DPEphos and xantphos provided somewhat higher conversions (Table 1, entries 10-11). In the case of rac-BINAP, the substrate was left almost intact (Table 1, entry 12). The aforementioned unsuccessful results led us to a screening of ferrocene-based phosphine ligands. The addition of dppf prevented the semihydrogenation reaction (Table 1, entry 13). In the case of other symmetrical ligands, including tbppf, dippf, and dcypf, a small amount of the substrate was consumed, providing mixtures of isomers (Table 1, entries 14-16). Surprisingly, the employment of unsymmetrical tbppf gave a complete conversion and excellent selectivity without any trace of the overreduction product (Table 1 , entry 17 ).

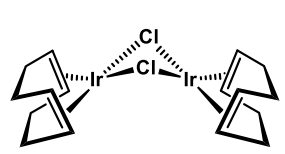

$\left[\operatorname{lr}(\mathrm{COD}) \mathrm{Cl}_{2}\right.$

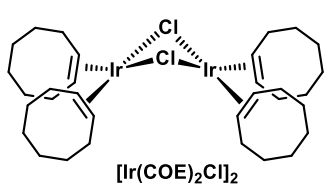

Figure 1. Tested Iridium Complexes.

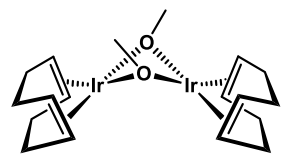

$[\operatorname{Ir}(\mathrm{COD}) \mathrm{OMe}]_{2}$

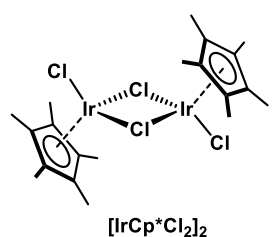

When $[\operatorname{Ir}(\mathrm{COD}) \mathrm{Cl}]_{2}$ was replaced with $[\operatorname{Ir}(\mathrm{COD}) \mathrm{OMe}]_{2}$ or $\left[\mathrm{IrCp}^{*} \mathrm{Cl}_{2}\right]_{2}$, only a tiny part of the substrate was converted to products (Table 1, entries 18,20). Application of $\left[\operatorname{Ir}(\mathrm{COE})_{2} \mathrm{Cl}\right]_{2}$ gave similar results to $[\operatorname{Ir}(\mathrm{COD}) \mathrm{Cl}]_{2}$, which was used for further studies (Table 1, entry 19).

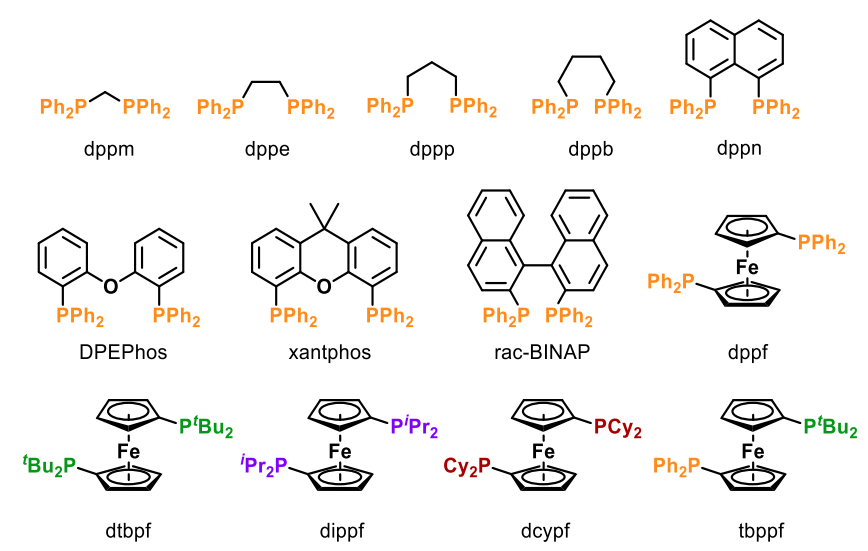

Figure 2. Tested phosphine bidentate ligands.

Changing THF for MeCN or DMF resulted in much lower conversions (Table 2, entries 1-2), while the use of acetone deteriorated selectivity (Table 2, entry 3). In contrast, the application of DME provided exclusively $(E)$-stilbene as a product (Table 2, entry 4). Temperature decrease significantly affected the conversion (Table 2 , entries $5-6$ ). It seems that the reaction needs to be car- 
ried out at a higher temperature than $60{ }^{\circ} \mathrm{C}$. Two times lower catalyst loading $(0.5 \mathrm{~mol} \%)$ was not sufficient to obtain the full conversion of the substrate (Table 2, entry 7), while the amount of 1.5 mol\% gave similar results to the initial conditions (Table 2, entry 8). Another intriguing phenomenon was the dependence of yield and stereoselectivity on ligand quantity. A higher amount of tbppf impedes the reaction (Table 2, entries 9-10), presumably due to excessive coordination to the metal center. While the loading of $3 \mathrm{~mol} \%$ did not affect the ratio of the isomers (Table 2, entry $11)$, a lower amount $(2 \mathrm{~mol} \%)$ led to the preponderance of $(Z)$-stilbene production (Table 1, entry 12). Analogously, this trend was found in the case of $\left[\operatorname{Ir}(\mathrm{COE})_{2} \mathrm{Cl}\right]_{2}$ (Table 2, entries 13-14). Even lower ligand loadings favor $(E)$-isomer formation again, albeit with over-reduction (Table 2, entries 15-16). In the case of symmetrical ligands, a quantity of $2 \mathrm{~mol} \%$ results in higher conversion (Table 2, entries 17-18). Finally, a decrease in the quantity of formic acid revealed that the minimal amount of this hydrogen donor should be higher than 40 equivalents to enable complete substrate conversion (Table 2, entries 19-20).

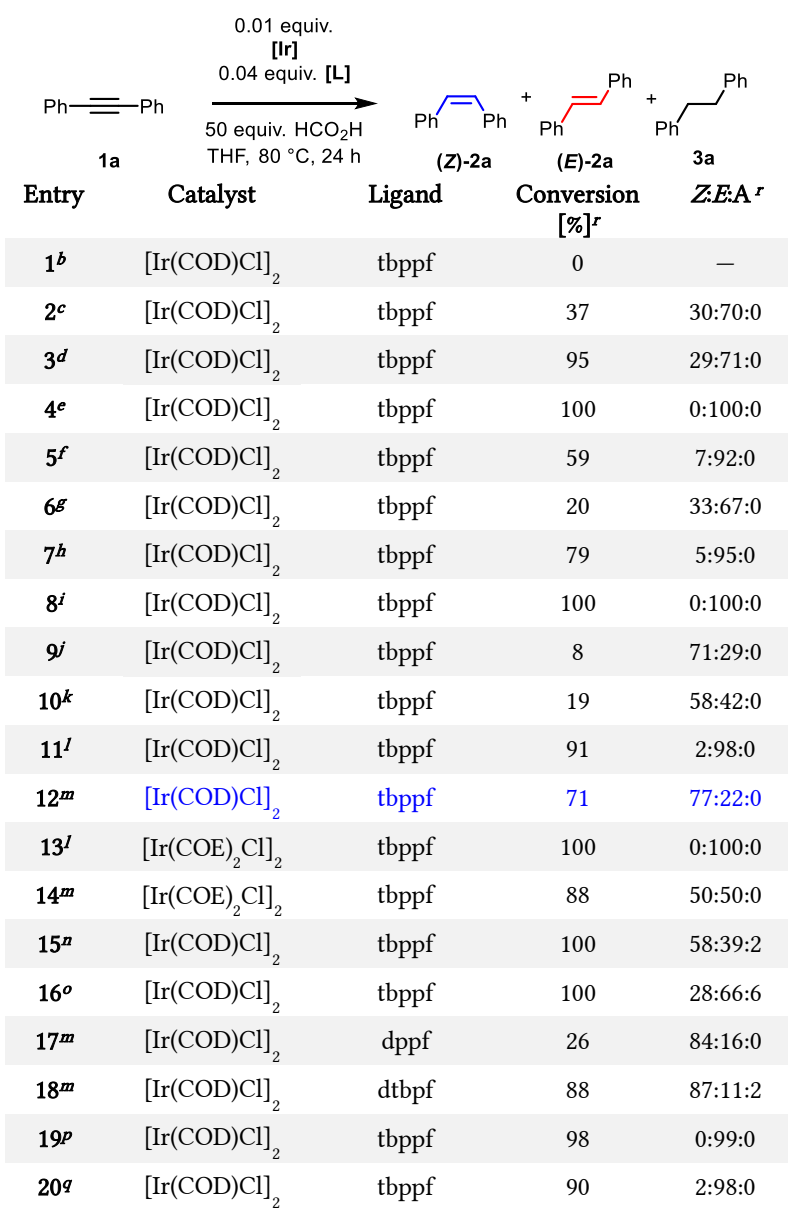

Table 2. Screening of The Reaction Conditions. ${ }^{a}$ Conditions: 0.01 equiv. [Ir], 0.04 equiv. [L], 50 equiv. $\mathrm{HCO}_{2} \mathrm{H}$, solvent, $80{ }^{\circ} \mathrm{C}$. Isolated yields. ${ }^{b}$ Solvent: MeCN. ${ }^{c}$ Solvent: DMF. ${ }^{d}$ Solvent: Acetone. ${ }^{e}$ Solvent: DME. ${ }^{\top}$ Temp.: $60{ }^{\circ} \mathrm{C} . g$ Temp.: $40{ }^{\circ} \mathrm{C}$. ${ }^{h} 0.005$ equiv. [Ir] ${ }^{i} 0.015$ equiv. [Ir]. ${ }^{j} 0.08$ equiv. [Ir]. ${ }^{k} 0.06$ equiv. [L]. ${ }^{1} 0.03$ equiv. [L]. ${ }^{m} 0.02$ equiv. [L]. ${ }^{n} 0.015$ equiv. [L]. ${ }^{o} 0.01$ equiv. [L]. ${ }^{p} 40$ equiv. $\mathrm{HCO}_{2} \mathrm{H} . q_{30}$ equiv. $\mathrm{HCO}_{2} \mathrm{H}$. ${ }^{r}$ Conversion and products distribution were determined by GC analysis.

Scope and limitations. Having in hand a fully optimized catalytic system, we tested a broad scope of different alkynes (Scheme 2). Diphenylacetylene and its derivatives were chosen to investigate the functional group tolerance. The presented methodology may be successfully applied towards 
both electron-withdrawing and electron-donating substituents. Simple tolane was transformed into $(E)$-stilbene $((E)-2 \mathrm{a})$ in excellent yield and stereoselectivity. Similar results were obtained in the case of compounds bearing methyl groups in para- $((E)-2 b)$ and meta- $((E)-2 c)$ positions to the double C-C bond. In contrast, the synthesis of the ortho- derivative $((E)-2 \mathrm{~d})$ demanded higher temperature and DME use, probably due to sterical hindrance. The substrate containing bulky tert-butyl group was smoothly transformed into the corresponding alkene $((E)-2 e)$. Halogenated compounds bearing fluoro-, chloro-, bromo- and even labile iodo- group $((E)-2 \mathrm{f}-\mathrm{i})$ were obtained in excellent yields and stereoselectivity.

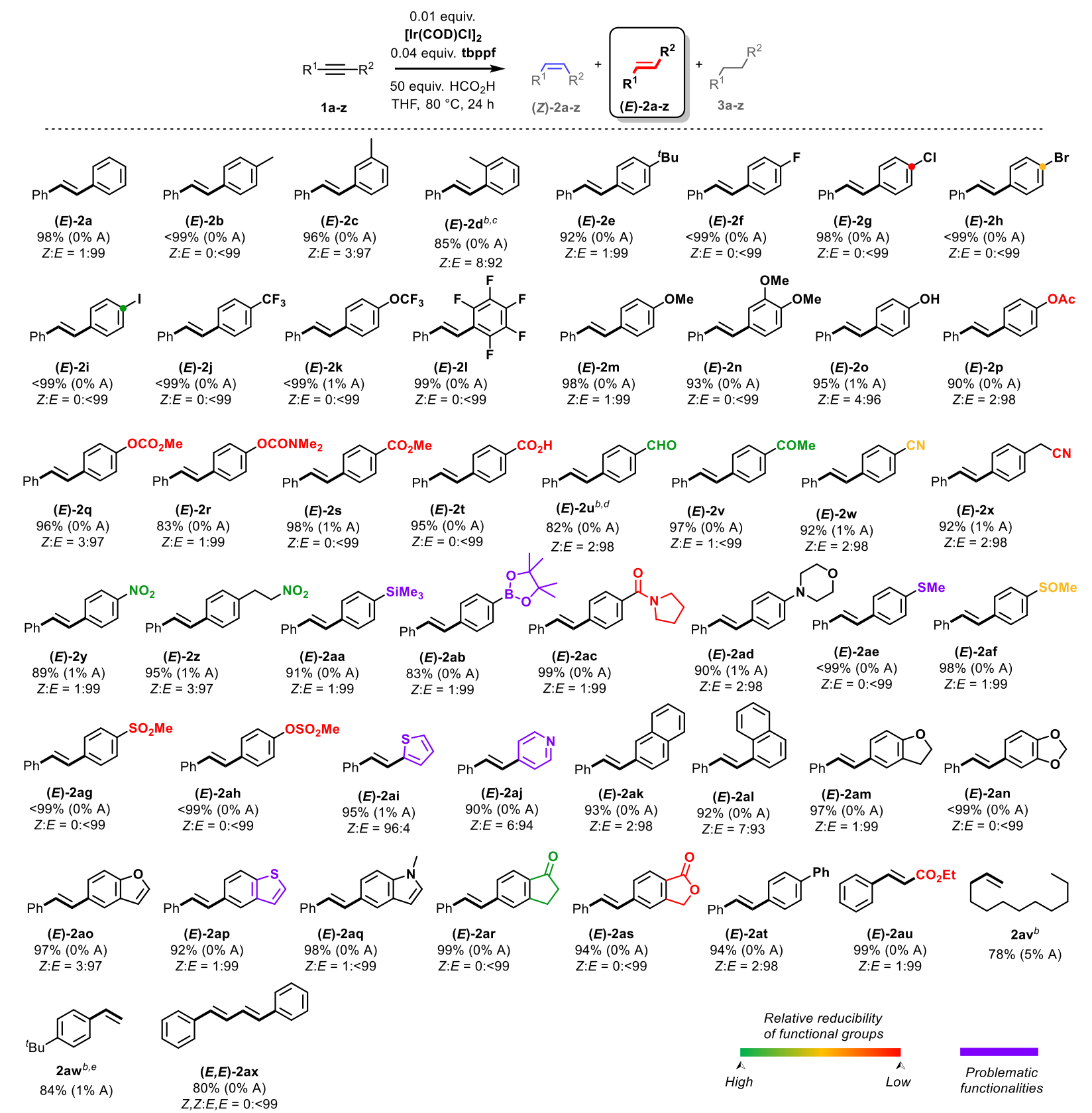

Scheme 2. Substrate Scope and Functional Groups Tolerance of The Title Reaction. ${ }^{a}$ General Conditions: 0.01 equiv. $[\operatorname{Ir}(\mathrm{COD}) \mathrm{Cl}]_{2}$, 0.04 equiv. tbppf, 50 equiv. $\mathrm{HCO}_{2} \mathrm{H}$, THF, $80^{\circ} \mathrm{C}$. Isolated yields. Products distribution was determined by GC or NMR analysis. ${ }^{b} \mathrm{GC}$ yield. ${ }^{\circ} \mathrm{DME}, 100{ }^{\circ} \mathrm{C} .{ }^{d} 3 \mathrm{~h} .{ }^{e} 0.02$ equiv. $[\operatorname{Ir}(\mathrm{COD}) \mathrm{Cl}]_{2}, 0.08$ equiv. tbppf.

Notably, the protodehalogenation process was not observed whatsoever. Analogous results were 
observed for alkynes containing trifluoromethyl-, trifluoromethoxy- or pentafluorobenzenegroup $((E)-2 \mathrm{j}-1)$. Semihydrogenation of substrates bearing methoxy- groups afforded the corresponding alkenes in very good yields and stereoselectivities $((E)-2 \mathrm{~m}-\mathbf{n})$. Phenol derivative $((E)-20)$ was produced effectively without an esterification reaction of the hydroxyl group. Furthermore, the described methodology was also compatible with various ester compounds, including acetate, carbonate, carbamate, and benzoate derivatives $((E)-2 \mathrm{p}-\mathbf{s})$. Similarly, stilbene with a carboxyl group was obtained in excellent yield and stereoselectivity $((E)-2 t)$. Observation of the paramount importance to the chemoselectivity of the investigated catalytic system was the lack of reduction of sensitive aldehyde and ketone compounds $((E)-2 \mathrm{u}-\mathrm{v})$. The former demanded a shorter reaction time $(3 \mathrm{~h})$ while the latter remained unaffected even after $24 \mathrm{~h}$. Both benzonitrile $((E)-2 \mathrm{w})$ and acetonitrile $((E)-2 \mathbf{x})$ derivatives were obtained successfully, and no reduction of the cyano group was observed in contrast to our previous system. Notably, the labile nitro groups of nitrobenzene $((E)-2 y)$ and nitroethane $((E)-2 z)$ based compounds were tolerated under the catalytic conditions. Apart from this, this methodology may be propitiously applied to problematic moieties bearing trimethylsilyl $((E)-2 \mathrm{aa})$ or pinacolborane $((E)-2 \mathrm{ab})$ groups. Nitrogen-containing compounds such as amides $((E)-2 \mathrm{ac})$ and amines $((E)$-2ad) were obtained in very good yields and stereoselectivities. Similar results were observed for products containing sulfur of different oxidation states, namely: sulfide $((E)-2 \mathrm{ae})$, sulfoxide $((E)-2 \mathrm{af})$, sulfone $((E)-2 \mathrm{ag})$, and sulfonate $((E)-2 \mathrm{ah})$.

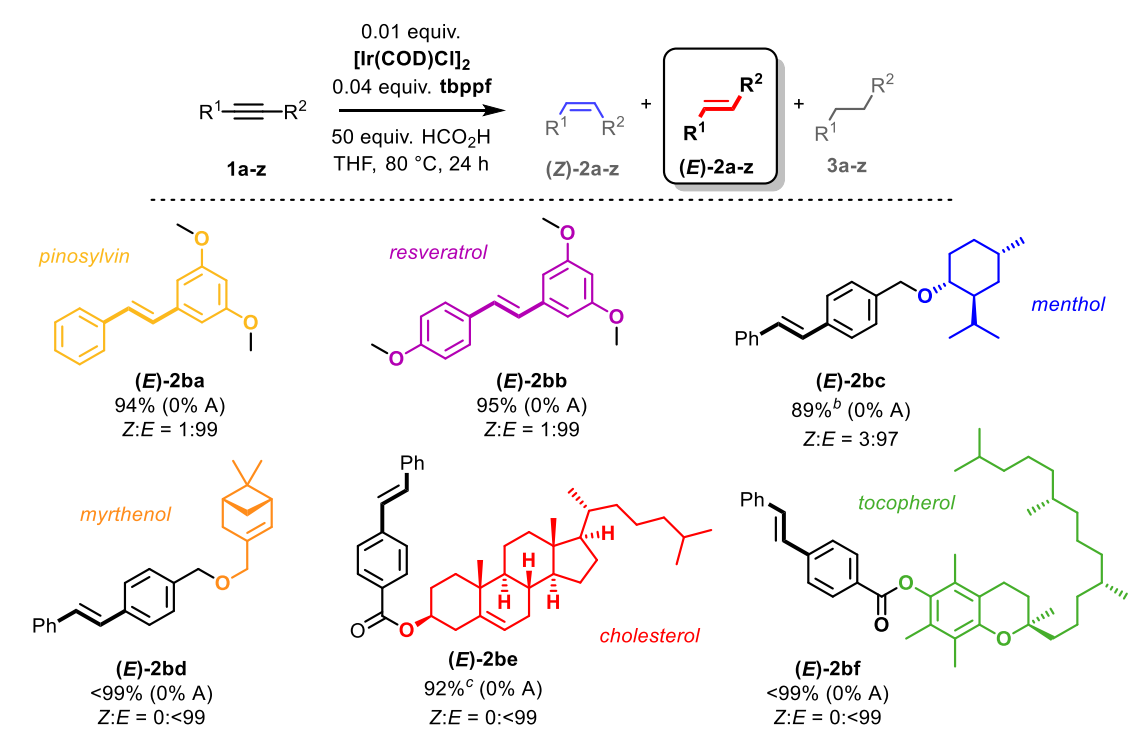

Scheme 3. Natural Products Derivatives Synthesis. ${ }^{a}$ General Conditions: 0.01 equiv. $[\operatorname{Ir}(\mathrm{COD}) \mathrm{Cl}]_{2}, 0.04$ equiv. tbppf, 50 equiv. $\mathrm{HCO}_{2} \mathrm{H}$, THF, $80{ }^{\circ} \mathrm{C}$. Isolated yields. Products distribution was determined by GC or NMR analysis. ${ }^{b} \mathrm{GC}$ yield. ${ }^{c} 0.015$ equiv. $[\operatorname{Ir}(\mathrm{COD}) \mathrm{Cl}]_{2}, 0.06$ equiv. tbppf.

In the case of the last three examples, no reduction of functional groups was found. Despite potential problems with coordination to the metal center of sulfur and nitrogen, compounds bearing thiophene $((E)$-2ai) and pyridine $((E)$-2aj) moieties were tolerated. The catalytic system was also applicable to derivatives of bicyclics such as naphthalene $((E)-2 \mathrm{ak}-1)$, dihydrobenzofurane $((E)$ - 
2am), benzodioxole $((E)$-2an), benzofurane $((E)$-2ao), benzothiophene $((E)$-2ap), and indole $((E)$ 2aq). Excellent results were obtained in the case of bicyclic ketone- ((E)-2ar), lactone- $((E)-2 \mathrm{as})$, or biphenyl-based compounds $((E)$-2at). Our methodology may be applied to other types of alkynes, including aryl-alkyl ((E)-2au) and terminal ones.

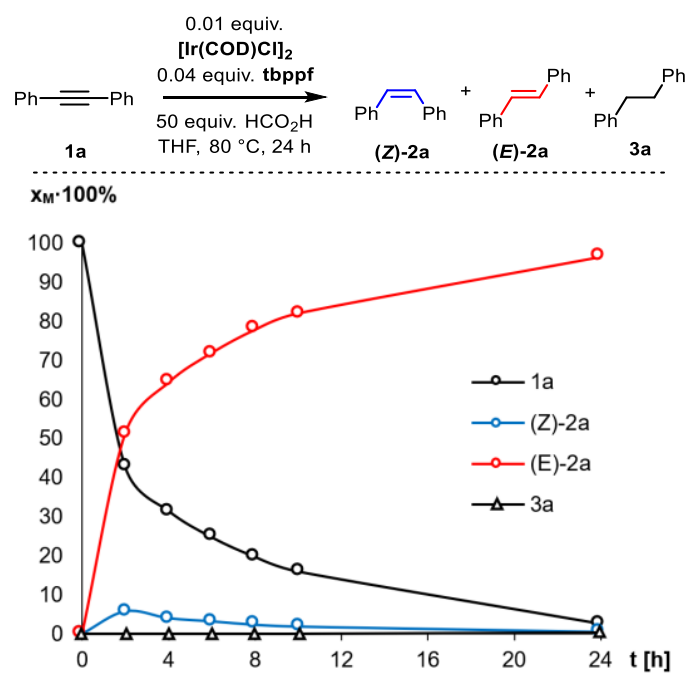

Scheme 4. Reaction Profile for 1a Semihydrogenation. ${ }^{a}$ Conditions: 0.01 equiv. $[\operatorname{Ir}(\mathrm{COD}) \mathrm{Cl}]_{2}, 0.04$ equiv. tbppf, 50 equiv. $\mathrm{HCO}_{2} \mathrm{H}, \mathrm{THF}, 80^{\circ} \mathrm{C}$. Conversion and products distribution were determined by $\mathrm{GC}$ analysis.

Dodec-1-yne gave a somewhat lower yield due to the production of regio-isomers $((E)-2 \mathrm{av})$, while the phenylacetylene derivative demanded higher catalyst loading $((E)-2 a w)$. Finally, 1,3-diyne was transformed to the corresponding diene $((E)$-2ax $)$ in good yield and stereoselectivity under catalytic conditions.

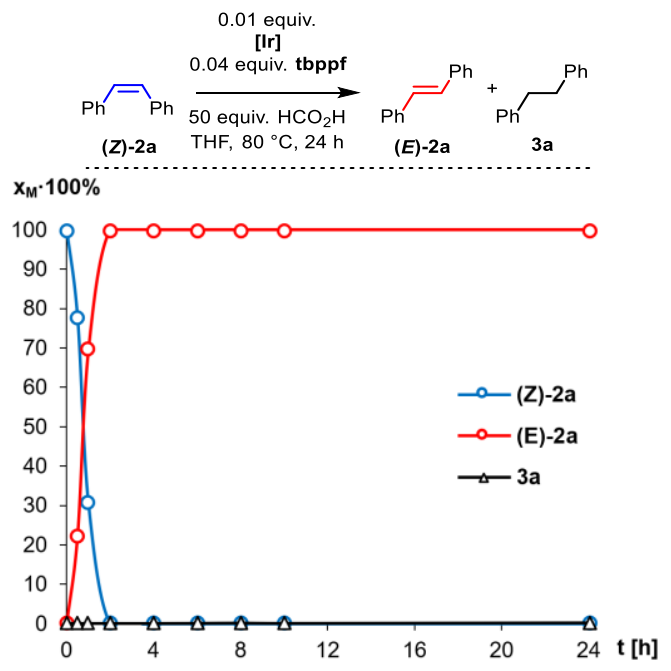

Scheme 5. Reaction Profile for (Z)-2a Isomerization. ${ }^{a}$ Conditions: 0.01 equiv. $[\operatorname{Ir}(\mathrm{COD}) \mathrm{Cl}]_{2}, 0.04$ equiv. tbppf, 50 equiv. $\mathrm{HCO}_{2} \mathrm{H}$, THF, $80{ }^{\circ} \mathrm{C}$. Conversion and products distribution were determined by $\mathrm{GC}$ analysis.

The broad scope of the catalytic system was enriched with examples of natural products derivatives to evince its exceptional applicability (Scheme 3). Methylated stilbenoids - pinosylvin $((E)$ $2 \mathrm{ba})$ and resveratrol $((E)-2 \mathrm{bb})$ were efficiently synthesized in the semihydrogenation process. Sim- 
ilarly, this reaction yielded $(E)$-alkenes derived from terpenes - menthol $((E)-2 \mathbf{b c})$ and myrthenol ((E)-2bd). Eventually, higher molecular weight compounds, based on cholesterol $((E)-2 b e)$ or $\alpha-$ tocopherol $((E)-2 b f)$ skeleton, were obtained in high yields and stereoselectivity. Notably, the double $\mathrm{C}-\mathrm{C}$ bonds of myrthenol and cholesterol moieties remained unaffected during the reaction, which constitutes another proof of unprecedented chemoselectivity of the investigated system.

Mechanistic studies. The first step towards understanding the nature of the semihydrogenation process was an analysis of the model reaction mixture in time. The prepared mole fraction versus time profile revealed that $(Z)$-stilbene is produced in a small amount which decreases in time (Scheme 4). Furthermore, the negligible over-reduction product amount is invariable during the whole reaction. The former observation posed a question of whether $(E)$-stilbene was produced directly by semihydrogenation of diphenylacetylene or by the isomerization of $(Z)$-stilbene. The latter reaction was carried out and monitored in time to provide another profile which indicated a swift conversion of $(Z)$ - to $(E)$-stilbene within two hours (Scheme 5). Similarly, the corresponding over-reduction product was not observed even if the reaction was prolonged. Presumably, the $(E)$ isomer is formed in the sequence $(Z)$-semihydrogenation-isomerization, which is consistent with the literature.

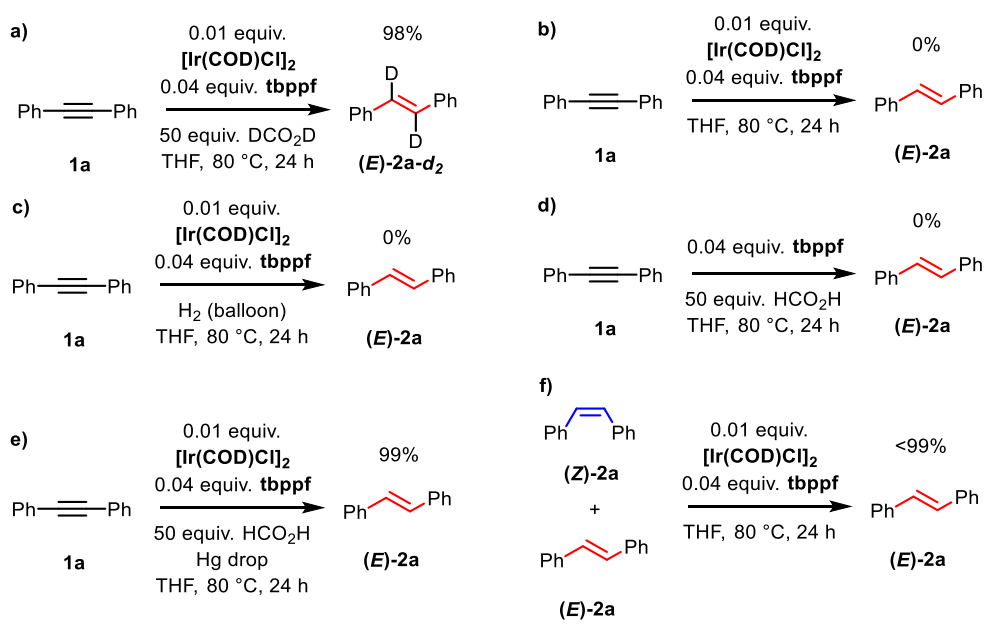

Scheme 6. Mechanistic experiments.

The role of formic acid as a hydrogen donor was proven by an experiment with $\mathrm{DCO}_{2} \mathrm{D}$ yeilding dideuterated $(E)$-stilbene $\left((E)-2 \mathrm{a}-\boldsymbol{d}_{2}\right)$ (Scheme 6a). Another evidence was delivered by the same model reaction performed in the absence of $\mathrm{HCO}_{2} \mathrm{H}$, which did not produce the desired alkene (Scheme 6b). Replacing formic acid with gaseous hydrogen was ineffective in terms of the semihydrogenation process (Scheme 6c). This indicates transfer- rather than direct hydrogenation despite the presence of hydrogen in the model reaction, which is evolved in the decomposition of $\mathrm{HCO}_{2} \mathrm{H}$. Expectedly, the reaction does not occur without the iridium precursor, which forms the catalytically active species (Scheme 6d). The semihydrogenation process of the model substrate 
was not affected by the addition of a mercury drop, which indicates the homogeneity of the catalytic system (Scheme 6e). An equimolar mixture of $(Z)$ - and $(E)$-stilbene is transformed exclusively to the $(E)$-isomer under the catalytic conditions (Scheme $6 \mathrm{f}$ ), which suggests that isomerization is favored over the over-reduction process.
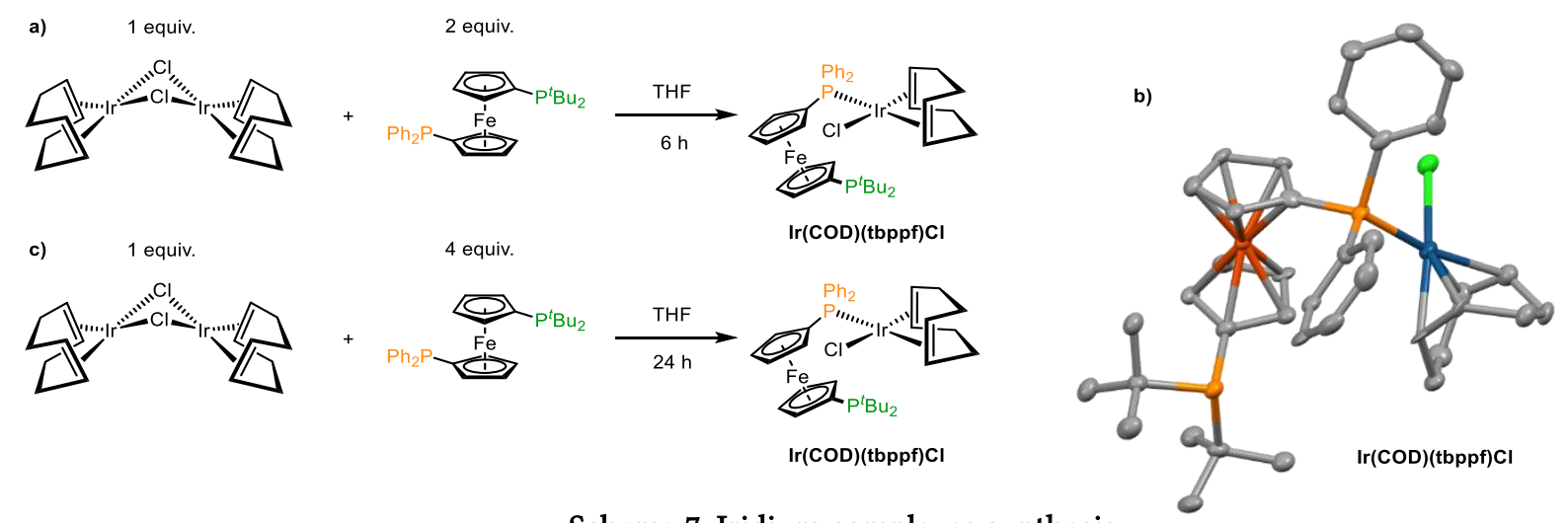

Scheme 7. Iridium complexes synthesis.

Subsequently, attempts were made to determine the active iridium species in the semihydrogenation process. Firstly, iridium complexes were generated and used without isolation in the model reaction (SI page S9). Depending on the ratio of $[\operatorname{Ir}(\mathrm{COD}) \mathrm{Cl}]_{2}$ to tbppf ligand, different isomers of the product were obtained. A proportion of 1:2 led to the formation of $(Z)$-stilbene as a major product, while a ratio of 1:4 gave exclusively $(E)$-stilbene. This intriguing observation indicates that ligand loading may be used to control the stereoselectivity of the semihydrogenation. Reaction of $\left[\operatorname{Ir}(\mathrm{COD}) \mathrm{Cl}_{2}\right.$ with 2 equiv. of tbppf resulted in the formation of the complex $\operatorname{Ir}(\mathrm{COD})($ tbppf)Cl (Scheme 7a). Unexpectedly, obtained X-ray analysis revealed that only diphenyl phosphine moiety of the bidentate ligand is coordinated to the metal center (Scheme $7 \mathrm{~b}$ ) what is consistent with ${ }^{31} \mathrm{P}$ NMR analysis of the free ligand and the complex (SI page 10). Surprisingly, when the amount of ligand was increased to 4 equiv., the same complex was produced, and the rest of the tbbpf remained unreacted (Scheme 7c) (SI page 10). Presumably, the ligand excess is needed in further stages of production of the catalytically active species. Finally, NMR analysis of the complexes produced in the reaction between $[\operatorname{Ir}(\mathrm{COD}) \mathrm{Cl}]_{2}$ and symmetrical ligand in ratio $1: 2$ was carried out. The use of dppf led to the formation of a complex having only one signal in ${ }^{31} \mathrm{P}$ NMR, suggesting coordination of both phosphines (SI page 10-11). On the contrary, a spectrum of the complex synthesized from dtbpf exhibits two signals, indicating single coordination (SI page 12). The above observations may explain differences in catalytic activities between complexes bearing unsymmetrical and symmetrical ferrocene-based ligands. Presumably, double coordination of dppf impedes coordination of triple $\mathrm{C}-\mathrm{C}$ bond to the metal center (Table 2, entry 17), while bulky dtbpf ligand favors $(Z$ )-semihydrogenation (Table 2, entry 18) similarly to tbppf (Table 2 , entry 12). A higher ratio of $[\operatorname{Ir}(\mathrm{COD}) \mathrm{Cl}]_{2}$ to dtbpf increases steric hindrance and thus obstructs the reaction (Table 1, entry 14 ) in comparison to tbppf (Table 1, entry 17). 
The previous experiments and the studied literature 24,28 allowed us to propose a plausible mechanism (Scheme 8). Firstly, the reaction between the precatalyst and formic acid results in the formation of iridium hydride, which participates in three cycles. The 'Cycle $A$ ' concerning $(Z)$ semihydrogenation embraces metal center coordination to the triple $\mathrm{C}-\mathrm{C}$ bond, hydrometallation, and production of $(Z)$-alkene, which is isomerized in the 'Cycle $B$ ' via the addition of iridium hydride. The necessity of using an excess of formic acid (Table 2) is elucidated by its decomposition in a dehydrogenation reaction $($ Cycle $C)$.

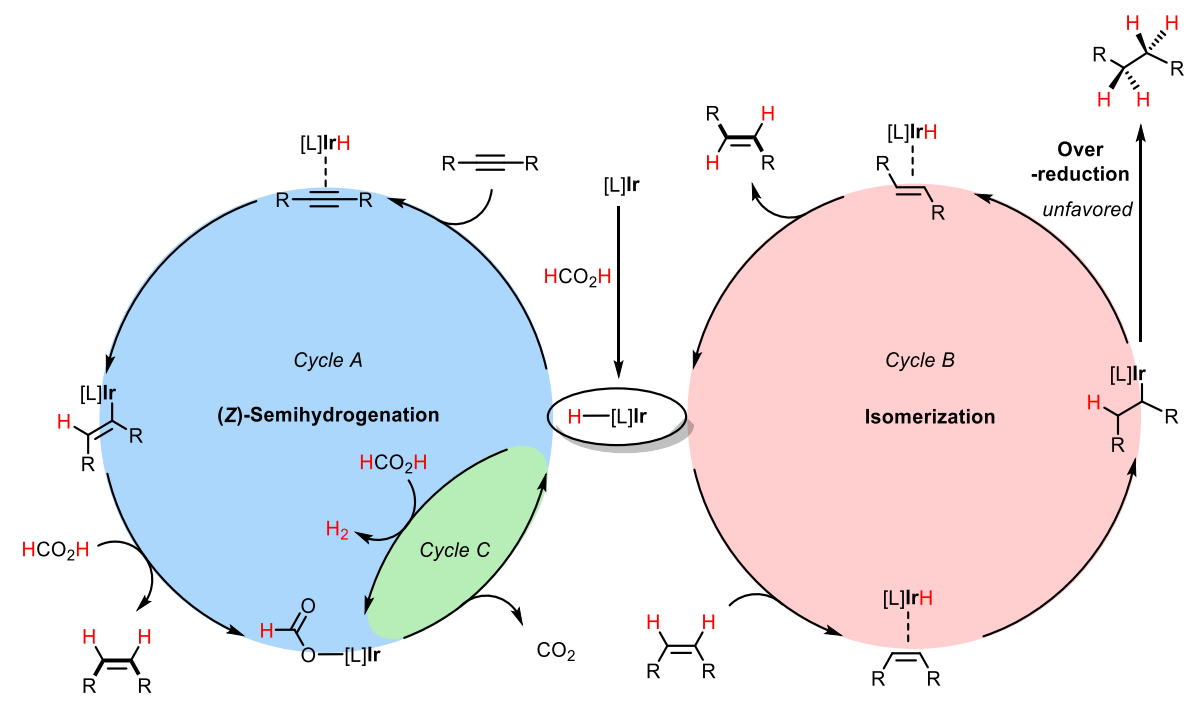

Scheme 8. Proposed Mechanism.

\section{CONCLUSION}

In summary, a novel iridium-catalyzed $(E)$-selective system for alkyne semihydrogenation was developed. The catalyst is produced in situ from commercially available $[\operatorname{Ir}(\mathrm{COD}) \mathrm{Cl}]_{2}$ and unsymmetrical ferrocene-based phosphine ligand (tbppf) in the presence of formic acid, which plays the role of a hydrogen donor. Interestingly, an application of symmetrical ligands fails to provide semihydrogenation products, which was the observation of paramount importance to the catalytic activity. Furthermore, stereoselectivity depends on ligand loading, which may be altered to obtain the $(Z)$-isomer. The presented method is distinguished by unprecedented chemoselectivity and excellent stereoselectivity. The broad scope of tested substrates proved that reducible or problematic functionalities such as halogens, ketones, aldehydes, nitro, nitriles, esters, sulfides, sulfoxides, sulfones, sulfonates, trimethylsilyl, pinacolborane, and heterocycles are tolerated under the reductive conditions. The methodology is not limited to aryl-aryl alkynes but may be applied to other types of substrates (aryl-alkyl, terminal, and diynes). The catalytic system may be propitiously applied to synthesis natural products derivatives, even those containing unsaturated C-C bonds. Notably, there is no need to control semihydrogenation in the time since the over- 
reduction process is negligible even if the reaction is prolonged. Another potential application of this protocol is the efficient isomerization of $(Z)$-alkenes into $(E)$-isomers. The intriguing difference of catalytic activity between unsymmetrical and symmetrical ferrocene-based ligands was ascribed to divergent coordination and steric hindrance. The mechanistic studies allowed us to propose a plausible mechanism embracing the formation of iridium hydride, which participates in three catalytic cycles: $(Z)$-semihydrogenation, isomerization, and dehydrogenation of formic acid. The presented methodology constitutes a solution to the limitations of the existing catalytic systems and sheds light on mechanistic aspects of iridium-catalyzed alkynes semihydrogenation.

\section{ACKNOWLEDGMENTS}

The authors are grateful to the National Science Centre (Poland) for the NCN Opus grant no. UMO-2017/25/B/ST5/01274.

\section{AUTHOR INFORMATION}

Corresponding Author: Karol Grela:prof.grela@gmail.com, Rafał Kusy: raphal.qs@gmail.com

Author Contributions: †These authors contributed equally.

\section{REFERENCES}

(1) Andersson, P. G., Munslow, I. J., Eds. Modern Reduction Methods; Wiley-VCH Verlag GmbH \& Co. KGaA: Weinheim, 2008

(2) (a) Handbook of Homogeneous Hydrogenation, ed. J. G. de Vries and C. J. Elsevier, Wiley-VCH, Weinheim, 2007; (b) S. Siegel, Heterogeneous Catalytic Hydrogenation of $C=C$ and $C \equiv C$, in Comprehensive Organic Synthesis, Vol. 8 Reduction, ed. B. M. Trost and I. Fleming, Pergamon Press, Oxford, 1993, pp. 417-443; (c) H. Takaya, Homogeneous Catalytic Hydrogenation of $C=C$ and $C \equiv C$, in Comprehensive Organic Synthesis Vol. 8 Reduction, ed. B. M. Trost and I. Fleming, Pergamon Press, Oxford, 1993, pp. 443-471.

(3) Gu, Y.; Norton, J. R.; Salahi, F.; Lisnyak, V. G.; Zhou, Z.; Snyder, S. A. Highly Selective Hydrogenation of $\mathrm{C}=\mathrm{C}$ Bonds Catalyzed by a Rhodium Hydride. J. Am. Chem. Soc. 2021, 143 (25), 9657-9663.

(4) Amghizar, I.; Vandewalle, L. A.; Van Geem, K. M.; Marin, G. B. New Trends in Olefin Production. Engineering 2017, 3(2), 171-178.

(5) Akinwumi, B. C.; Bordun, K.-A. M.; Anderson, H. D. Biological Activities of Stilbenoids. Int. J. Mol. Sci. 2018, $19(3), 792$.

(6) Navarro, G.; Martínez -Pinilla, E.; Ortiz, R.; Noé, V.; Ciudad, C. J.; Franco, R. Resveratrol and Related Stilbenoids, Nutraceutical/Dietary Complements with Health-Promoting Actions: Industrial Production, Safety, and the Search for Mode of Action. Compr. Rev. Food Sci. Food Saf. 2018, 17 (4), 808-826.

(7) Gusevskaya, E. V.; Jiménez-Pinto, J.; Börner, A. Hydroformylation in the Realm of Scents. ChemCatChem 2014, 6 (2), 382-411.

(8) Lindlar, H. Ein Neuer Katalysator Für Selektive Hydrierungen. Helv. Chim. Acta 1952, 35 (2), 446-450.

(9) Campbell, K. N.; Eby, L. T. The Preparation of Higher Cis and Trans Olefins1. J. Am. Chem. Soc. 1941, $63(1), 216-219$.

(10) Campbell, K. N.; Eby, L. T. The Reduction of Multiple Carbon-Carbon Bonds. III. Further Studies on the Preparation of Olefins from Acetylenes1,2. J. Am. Chem. Soc. 1941, 63 (10), 2683-2685.

(11) (a) La Pierre, H. S.; Arnold, J.; Toste, F. D. Z-Selective Semihydrogenation of Alkynes Catalyzed by a Cationic Vanadium Bisimido Complex. Angew. Chem. Int. Ed. 2011, 50 (17), 3900-3903. (b) Radkowski, K.; Sundararaju, B.; Fürstner, A. A Functional-Group-Tolerant Catalytic trans Hydrogenation of Alkynes. 
Angew. Chem. Int. Ed. 2013, 52 , 355-360. (c) Srimani, D.; Diskin-Posner, Y.; Ben-David, Y.; Milstein, D. Iron Pincer Complex Catalyzed, Environmentally Benign, E-Selective Semi-Hydrogenation of Alkynes. Angew. Chem. Int. Ed. 2013, 52, 14131-14134. (d) Karunananda, M. K.; Mankad, N. P. E-Selective SemiHydrogenation of Alkynes by Heterobimetallic Catalysis.J. Am. Chem. Soc. 2015, 137, 14598-14601. (e) Neumann, K. T.; Klimczyk, S.; Burhardt, M. N.; Bang-Andersen, B.; Skrydstrup, T.; Lindhardt, A. T. Direct trans-Selective Ruthenium-Catalyzed Reduction of Alkynes in Two-Chamber Reactors and Continuous Flow. ACS Catal. 2016, 6, 4710-4714. (f) Tokmic, K.; Fout, A. R. Alkyne Semihydrogenation with a WellDefined Nonclassical $\mathrm{Co}-\mathrm{H}_{2}$ Catalyst: $\mathrm{A} \mathrm{H}_{2}$ Spin on Isomerization and E-Selectivity. J. Am. Chem. Soc. 2016, 138, 13700-13705. (g) Furukawa, S.; Komatsu, T. Selective Hydrogenation of Functionalized Alkynes to (E)-Alkenes, Using Ordered Alloys as Catalysts. ACS Catal. 2016, 6, 2121-2125. (h) Fedorov, A.; Liu, H.J.; Lo, H.-K.; Copéret, C. Silica-Supported Cu Nanoparticle Catalysts for Alkyne Semihydrogenation: Effect of Ligands on Rates and Selectivity. J. Am. Chem. Soc. 2016, 138 (50), 16502-16507. (i) Chen, F.; Kreyenschulte, C.; Radnik, J.; Lund, H.; Surkus, A.-E.; Junge, K.; Beller, M. Selective Semihydrogenation of Alkynes with N-Graphitic-Modified Cobalt Nanoparticles Supported on Silica. ACS Catal. 2017, 7, 15261532. (j) Gorgas, N.; Brünig, J.; Stöger, B.; Vanicek, S.; Tilset, M.; Veiros, L. F.; Kirchner, K. Efficient ZSelective Semihydrogenation of Internal Alkynes Catalyzed by Cationic Iron(II) Hydride Complexes. J. Am. Chem. Soc. 2019, 141, 17452-17458. (k) Li, W.; Cui, X.; Junge, K.; Surkus, A.-E.; Kreyenschulte, C.; Bartling, S.; Beller, M. General and Chemoselective Copper Oxide Catalysts for Hydrogenation Reactions. ACS Catal. 2019, 9, 4302-4307. (l) Ramirez, B. L.; Lu, C. C. Rare-Earth Supported Nickel Catalysts for Alkyne Semihydrogenation: Chemo- and Regioselectivity Impacted by the Lewis Acidity and Size of the Support. J. Am. Chem. Soc. 2020, 142, 5396-5407.

(12) Wang, D.; Astruc, D. The Golden Age of Transfer Hydrogenation. Chem. Rev. 2015, 115 (13), 66216686. https://doi.org/10.1021/acs.chemrev.5b00203.

(13) (a) Barrios-Francisco, R.; García, J. J. Semihydrogenation of Alkynes in the Presence of Ni(0) Catalyst Using Ammonia-Borane and Sodium Borohydride as Hydrogen Sources. Appl. Catal. Gen. 2010, 385 (1-2), 108-113. (b) Hartmann, C. E.; Jurčík, V.; Songis, O.; Cazin, C. S. J. Tandem Ammonia Borane Dehydrogenation/Alkene Hydrogenation Mediated by $\left[\mathrm{Pd}(\mathrm{NHC})\left(\mathrm{PR}_{3}\right)\right](\mathrm{NHC}=N$-Heterocyclic Carbene $)$ Catalysts. Chem. Commun. 2013, 49 , 1005-1007. (c) Korytiaková, E.; Thiel, N. O.; Pape, F.; Teichert, J. F. Copper(I)-Catalysed Transfer Hydrogenations with Ammonia Borane. Chem. Commun. 2017, 53, 732-735. (d) Brzozowska, A.; Azofra, L. M.; Zubar, V.; Atodiresei, I.; Cavallo, L.; Rueping, M.; El-Sepelgy, O. Highly Chemo- and Stereoselective Transfer Semihydrogenation of Alkynes Catalyzed by a Stable, Well-Defined Manganese(II) Complex. ACS Catal. 2018, 4103-4109. (e) Jaiswal, G.; Landge, V. G.; Subaramanian, M.; Kadam, R. G.; Zbořil, R.; Gawande, M. B.; Balaraman, E. N-Graphitic Modified Cobalt Nanoparticles Supported on Graphene for Tandem Dehydrogenation of Ammonia-Borane and Semihydrogenation of Alkynes. ACS Sustain. Chem. Eng. 2020, 8, 11058-11068 (f) Kusy, R.; Grela, K. Ligand-Free (Z)-Selective Transfer Semihydrogenation of Alkynes Catalyzed by in Situ Generated Oxidizable Copper Nanoparticles. Green Chem. 2021, 23 (15), 5494-5502.

(14) (a) Luo, F.; Pan, C.; Wang, W.; Ye, Z.; Cheng, J. Palladium-Catalyzed Reduction of Alkynes Employing HSiEt3: Stereoselective Synthesis of Trans- and Cis-Alkenes. Tetrahedron 2010, 66 (6), 1399-1403. https://doi.org/10.1016/j.tet.2009.11.098. (b) Semba, K.; Fujihara, T.; Xu, T.; Terao, J.; Tsuji, Y. CopperCatalyzed Highly Selective Semihydrogenation of Non-Polar Carbon-Carbon Multiple Bonds Using a Silane and an Alcohol. Adv. Synth. Catal. 2012, 354, 1542-1550. (c) Whittaker, A. M.; Lalic, G. Monophasic Catalytic System for the Selective Semireduction of Alkynes. Org. Lett. 2013, 15, 1112-1115. (d) Prabusankar, G.; Sathyanarayana, A.; Raju, G.; Nagababu, C. Methanol as a Hydrogen Source in Pd(II)$\operatorname{Bis}(N$-Heterocyclic Carbene) Mediated Catalytic Semi-Reduction of Alkyne Under Mild Condition. Asian J. Org. Chem. 2017, 6, 1451-1459

(15) (a) Kaicharla, T.; Zimmermann, B. M.; Oestreich, M.; Teichert, J. F. Using Alcohols as Simple H2Equivalents for Copper-Catalysed Transfer Semihydrogenations of Alkynes. Chem. Commun. 2019, 55 (89), 13410-13413. (b) Bao, H.; Zhou, B.; Jin, H.; Liu, Y. Copper-Catalyzed Z-Selective Semihydrogenation of Alkynes Using Ethanol as a Hydrogen Donor J. Org. Chem. 2019, 84, 3579-3589. (c) Sklyaruk, J.; Zubar, V.; Borghs, J. C.; Rueping, M. Methanol as the Hydrogen Source in the Selective Transfer Hydrogenation of Alkynes Enabled by a Manganese Pincer Complex. Org. Lett. 2020, 22, 6067-6071.

(16) Han, X.; Hu, J.; Chen, C.; Yuan, Y.; Shi, Z. Copper-Catalysed, Diboron-Mediated Cis-Dideuterated Semihydrogenation of Alkynes with Heavy Water. Chem. Commun. 2019, 55 (48), 6922-6925. https://doi.org/10.1039/C9CC03213D.

(17) (a) Wienhöfer, G.; Westerhaus, F. A.; Jagadeesh, R. V.; Junge, K.; Junge, H.; Beller, M. Selective IronCatalyzed Transfer Hydrogenation of Terminal Alkynes. Chem. Commun. 2012, 48 (40), 4827-4829. (b) Li, S.-S.; Tao, L.; Wang, F.-Z.-R.; Liu, Y.-M.; Cao, Y. Heterogeneous Gold-Catalyzed Selective Semireduction of 
Alkynes Using Formic Acid as Hydrogen Source. Adv. Synth. Catal. 2016, 358, 1410-1416. (c) Iwasaki, R.; Tanaka, E.; Ichihashi, T.; Idemoto, Y.; Endo, K. Semireduction of Alkynes Using Formic Acid with Reusable Pd-Catalysts. J. Org. Chem. 2018, 83, 13574-13579.

(18) Mellmann, D.; Sponholz, P.; Junge, H.; Beller, M. Formic Acid as a Hydrogen Storage Material Development of Homogeneous Catalysts for Selective Hydrogen Release. Chem. Soc. Rev. 2016, 45 (14), 3954-3988.

(19) Schabel, T.; Belger, C.; Plietker, B. A Mild Chemoselective Ru-Catalyzed Reduction of Alkynes, Ketones, and Nitro Compounds. Org. Lett. 2013, 15(11), 2858-2861.

(20) Ekebergh, A.; Begon, R.; Kann, N. Ruthenium-Catalyzed E-Selective Alkyne Semihydrogenation with Alcohols as Hydrogen Donors. J. Org. Chem. 2020, 85 (5), 2966-2975.

(21) Li, K.; Yang, C.; Chen, J.; Pan, C.; Fan, R.; Zhou, Y.; Luo, Y.; Yang, D.; Fan, B. Anion Controlled Stereodivergent Semi-Hydrogenation of Alkynes Using Water as Hydrogen Source. Asian J. Org. Chem. 2021, $10(8), 2143-2146$.

(22) Li, K.; Khan, R.; Zhang, X.; Gao, Y.; Zhou, Y.; Tan, H.; Chen, J.; Fan, B. Cobalt Catalyzed Stereodivergent Semi-Hydrogenation of Alkynes Using $\mathrm{H} 2 \mathrm{O}$ as the Hydrogen Source. Chem. Commun. 2019, 55 (39), 5663-5666.

(23) Yang, J.; Wang, C.; Sun, Y.; Man, X.; Li, J.; Sun, F. Ligand-Controlled Iridium-Catalyzed Semihydrogenation of Alkynes with Ethanol: Highly Stereoselective Synthesis of E- and Z-Alkenes. Chem. Commun. 2019, 55(13), 1903-1906.

(24) Wang, Y.; Huang, Z.; Huang, Z. Catalyst as Colour Indicator for Endpoint Detection to Enable Selective Alkyne Trans -Hydrogenation with Ethanol. Nat. Catal. 2019, 2 (6), 529.

(25) Richmond, E.; Moran, J. Ligand Control of E/Z Selectivity in Nickel-Catalyzed Transfer Hydrogenative Alkyne Semireduction. J. Org. Chem. 2015, 80 (13), 6922-6929.

(26) Li, H.-C.; An, C.; Wu, G.; Li, G.-X.; Huang, X.-B.; Gao, W.-X.; Ding, J.-C.; Zhou, Y.-B.; Liu, M.-C.; Wu, H.-Y. Transition-Metal-Free Highly Chemoselective and Stereoselective Reduction with Se/DMF/H2O System. Org. Lett. 2018, 20 (18), 5573-5577.

(27) Chen, Z.; Luo, M.; Wen, Y.; Luo, G.; Liu, L. Transition-Metal-Free Semihydrogenation of Diarylalkynes: Highly Stereoselective Synthesis of Trans-Alkenes Using Na2S.9H2O. Org. Lett. 2014, 16 (11), 3020-3023.

(28) Fu, S.; Chen, N.-Y.; Liu, X.; Shao, Z.; Luo, S.-P.; Liu, Q. Ligand-Controlled Cobalt-Catalyzed Transfer Hydrogenation of Alkynes: Stereodivergent Synthesis of Z- and E-Alkenes. J. Am. Chem. Soc. 2016, 138 (27), 8588-8594.

(29) Rao, S.; Prabhu, K. R. Stereodivergent Alkyne Reduction by Using Water as the Hydrogen Source. Chem. - Eur. J. 2018, 24 (52), 13954-13962.

(30) Fetzer, M. N. A.; Tavakoli, G.; Klein, A.; Prechtl, M. H. G. Ruthenium-Catalyzed E-Selective Partial Hydrogenation of Alkynes under Transfer-Hydrogenation Conditions Using Paraformaldehyde as Hydrogen Source. ChemCatChem 2021, 13(5), 1317-1325.

(31) Luo, X.; Chen, X.; Chen, L.; Zhang, K.; Li, Y. Xanthate-Mediated Synthesis of (E)-Alkenes by SemiHydrogenation of Alkynes Using Water as the Hydrogen Donor. Chem. Commun. 2019, 55 (15), 2170-2173.

(32) Prasanna, R.; Guha, S.; Sekar, G. Proton-Coupled Electron Transfer: Transition-Metal-Free Selective Reduction of Chalcones and Alkynes Using Xanthate/Formic Acid. Org. Lett. 2019, 21 (8), 2650-2653.

(33) Gong, D.; Hu, B.; Yang, W.; Kong, D.; Xia, H.; Chen, D. A Bidentate Ru(II)-NC Complex as a Catalyst for Semihydrogenation of Alkynes to (E)-Alkenes with Ethanol. Organometallics 2020, 39(6), 862-869.

(34) Kusy, R.; Grela, K. E- and Z-Selective Transfer Semihydrogenation of Alkynes Catalyzed by Standard Ruthenium Olefin Metathesis Catalysts. Org. Lett. 2016, 18 (23), 6196-6199. 


\section{A TABLE OF CONTENTS:}

$$
\begin{array}{ll}
0.01 \text { equiv. } \\
\text { ligand }
\end{array}
$$

